\title{
Decreased expression of haemoglobin beta (HBB) gene in anaplastic thyroid cancer and recovory of its expression inhibits cell growth
}

\author{
M Onda*,', J Akaishi', S Asaka', J Okamoto', S Miyamoto', K Mizutani', A Yoshida ${ }^{2}, \mathrm{~K} \mathrm{Ito}^{3}$ and M Emi' \\ 'Department of Molecular Biology, Institute of Gerontology, Nippon Medical School, Kawasaki, Japan; 'Kanagawa Prefectural Cancer Center, \\ Department of Surgery, Kanagawa, Japan; ${ }^{3}$ to Hospital, Tokyo, Japan
}

Anaplastic thyroid cancer (ATC) is one of the most fulminant and foetal diseases in human malignancies. However, the genetic alterations and carcinogenic mechanisms of ATC are still unclear. Recently, we investigated the gene expression profile of II anaplastic thyroid cancer cell lines (ACL) and significant decreased expression of haemoglobin beta (HBB) gene in ACL. Haemoglobin beta is located at I I I 5.5, where loss of heterozygosity $(\mathrm{LOH})$ was reported in various kinds of cancers, including ATC, and it has been suggested that novel tumour suppressor genes might exist in this region. In order to clarify the meaning of decreased expression of HBB in ATC, the expression status of HBB was investigated with ACL, ATC, papillary thyroid cancer (PTC) and normal human tissues. Haemoglobin beta showed significant decreased expression in ACLs and ATCs; however, in PTC, HBB expressed equal to the normal thyroid gland. In addition, HBB expressed in normal human tissues ubiquitously. To validate the tumour-suppressor function of HBB, cell growth assay was performed. Forced expression of HBB in KTA2 cell, which is a kind of ACL, significantly suppressed KTA2 growth. The mechanism of downregulation of HBB in ATC is still unclear; however, our results suggested the possibility of $\mathrm{HBB}$ as a novel tumour-suppressor gene.

British Journal of Cancer (2005) 92, 2216-2224. doi:1 0. I038/sj.bjc.6602634 www.bjcancer.com

(c) 2005 Cancer Research UK

Keywords: haemoglobin beta (HBB); anaplastic thyroid cancer; tumour suppressor gene; papillary thyroid cancer; I I I 5.5

Anaplastic thyroid cancer is one of the most fulminant human malignancies, with a mean survival time among patients of less than 1 year after diagnosis, regardless of treatment (Passler et al, 1999; Voutilainen et al, 1999). It is considered that anaplastic thyroid cancer (ATC) is thought to arise mainly from a background of differentiated (papillary or follicular) cancer, on the basis of clinicopathological observations that ATC is often accompanied by such cells and that anaplastic tumours tend to arise in patients who had previously been treated for differentiated cancer of the thyroid (Nakamura et al, 1992; Kitamura et al, 2000a). Little is known about the genetic alterations in anaplastic thyroid cancer; only TP53 (Kitamura et al, 2000b) and beta-catenin (Garcia-Rostan et al, 1999) mutations have been discovered in ATC.

Recently, we investigated the gene expression profile of anaplastic thyroid cancer cell lines (ACLs) with cDNA microarray analysis (Onda et al, 2004a) and found the novel gene alterations that related to ATC/ACL carcinogenesis. The results of microarray analysis showed that haemoglobin beta (HBB) gene significantly decreased expression in ACLs, compared to the expression of

*Correspondence: Assist. Professor M Onda, Department of Molecular Biology Institute of Gerontology. Nippon Medical School, I-396, Kosugicho, Nakahara-ku, Kawasaki 2I I-8533, Japan; E-mail: monda@nms.ac.jp Received 20 September 2004; revised 7 March 2005; accepted 27 April 2005 normal thyroid gland. (Data will be provided upon request to the corresponding author.)

Haemoglobin beta locates at $11 \mathrm{p} 15.5$ and its main function is oxygen transporter activity (Thein et al, 1990). The normal adult haemoglobin ( $\mathrm{HbA}$ ) tetramer consists of two alpha chains and two beta chains (Yasuda et al, 2002), and it is known that mutant HBB causes sickle cell anaemia (Persons, 2003). Loss of heterozygosity $(\mathrm{LOH})$ of this locus has been reported in ovarian cancer (Launonen et al, 2000), glioma (Schiebe et al, 2001), breast cancer (Xu et al, 2001; Roy et al, 2003), lung cancer (Xu et al, 2001) and paediatric thyroid carcinoma (Pauws et al, 2001). In addition, our previous report showed up to $33 \%$ of $\mathrm{LOH}$ at $11 \mathrm{p} 15$ (D11S922) in anaplastic thyroid cancer (Kitamura et al, 2000a). Considering these facts, it is fascinating for us to investigate the relation between decreased expression of HBB and ACL/ATC progression.

In this study, we examined the expression status of $\mathrm{HBB}$ in ACLs, primary ATC and several normal human tissues with the reverse transcriptase-PCR (RT-PCR) method. In addition, protein expression was investigated in ATC, papillary thyroid cancer (PTC), follicular thyroid cancer (FTC), adenoma (FAD) and chronic thyroiditis $(\mathrm{CTH})$ using the immunohistochemical method, because, in some cases, it is considered that ATC might derive from PTC components (Nakamura et al, 1992; Ozaki et al, 1999; Kitamura et al,2000a). Next, the efficacy of the overexpression of $\mathrm{HBB}$ to cell growth in KTA2, which is an ACL and where no expression of $\mathrm{HBB}$ was confirmed, was evaluated. 


\section{MATERIALS AND METHODS}

\section{Anaplastic thyroid cancer cell lines}

In all, 11 cell lines that were derived from ATC, 8305c, 8505c, ARO, FRO, TTA1, TTA2, TTA3, KTA1, KTA2, KTA3 and KTA4 were used for this study. The $8305 \mathrm{c}$ and $8505 \mathrm{c}$ cell lines were maintained in Dulbecco's modified Eagle medium (Invitrogen, Carlsbad, CA, USA), ARO and FRO cell lines in minimum essential medium, and the other seven lines in RPMI 1640. All media contained $10 \%$ foetal bovine serum but no antibiotics. The cells were cultured in a $37^{\circ} \mathrm{C}$ incubator under $5 \% \mathrm{CO}_{2}$ atmosphere.

\section{Patients and specimens}

Primary ATC, PTC and noncancerous thyroid gland were excised from 10 patients who underwent surgery at the Ito Hospital, Tokyo; the samples were frozen immediately and stored at $-80^{\circ} \mathrm{C}$. All patients had given informed consent according to guidelines approved by the Institutional Research Board. All tumour specimens that we analysed contained more than $70 \%$ tumour cells.

For immunohistochemical analysis, 14 archived paraffinembedded samples of ATC and 15 PTC samples were used.

\section{RNA extraction and cDNA synthesis}

Extraction of RNA from cell lines and tissues was performed as described previously (Onda et al, 2004a, b). Using $5 \mu \mathrm{g}$ of RNA as a template, cDNAs were synthesised in the usual manner. Briefly, the template was mixed with $1 \mu \mathrm{l}$ of oligo $\mathrm{dT}_{12-18}$ (Invitrogen, Carlsbad, CA, USA), used for annealing primer and denatured at $70^{\circ} \mathrm{C}$ for $10 \mathrm{~min}$. Then, $200 \mathrm{U}$ of Reverse Transcriptase II (Wako Pure Chemical, Tokyo, Japan), reaction buffer, $40 \mathrm{U}$ of RNase inhibitor (Wako Pure Chemical) and $10 \mu \mathrm{mol} \mathrm{dNTPs} \mathrm{were} \mathrm{added.}$ This mixture was incubated at $42^{\circ} \mathrm{C}$ for $60 \mathrm{~min}$, after which the product was treated with $2 \mathrm{U}$ of RNase (Wako pure chemical) at $37^{\circ} \mathrm{C}$ for $20 \mathrm{~min}$.

\section{Semiquantitative RT-PCR}

In order to evaluate the expression of HBB in ACL, ATC, PTC and normal human tissues, semiquantitative RT-PCR (SQ-PCR) was performed. For the comparison, five normal thyroid samples were served as a control in SQ-PCR. To adjust the amount of transcribed cDNA, GAPDH was selected as an internal control and SQ-PCR experiments were carried out as previously described, after adjustment of the amount of template cDNA (Onda et al, 2004a). The primer sequences for GAPDH were $5^{\prime}$-ggaaggtgaaggtcggagt- $3^{\prime}$ (forward) and $5^{\prime}$-tgggtggaatcatattggaa- $3^{\prime}$ (reverse). Sequence information was collected from the NCBI GenBank (http:// www.ncbi.nlm.nih.gov/), and primers for HBB were designed with Primer 3 software (http://www-genome.wi.mit.edu/cgi-bin/primer/ primer3_www.cgi). The HBB forward primer was $5^{\prime}$-ggagatgcctcagaaactgc- $3^{\prime}$ and the reverse primer was $5^{\prime}$-aggttggaggtcggaaagtt- $3^{\prime}$. SQ-PCR experiments were performed with $1 \mu \mathrm{l}$ of cDNA for template, $5 \mathrm{U}$ of Takara EX Taq (Takara, Otsu, Japan), $1 \times$ PCR buffer $\left(10 \mathrm{~mm}\right.$ Tris- $\left.\mathrm{HCl}, 50 \mathrm{~mm} \mathrm{KCl}, 1.5 \mathrm{~mm} \mathrm{MgCl}_{2}\right)$ and reverse primers in $30 \mu \mathrm{l}$ of total reaction mixture. PCR conditions for each gene were optimised in their respective linear phases of amplification.

For the evaluation of differences of HBB expression between ACL, ATC, PTC and normal thyroid gland, $10 \mu \mathrm{l}$ of each SQ-PCR product was electrophoresed on a $2.0 \%$ agarose gel and stained with ethidium bromide. After staining, the density of each sample spot was measured by AlphaImager 3300 (AlphaIonotech, San Leandro, CA, USA) with background revision. All SQ-PCR experiments were duplicated.

\section{Quantitative RT-PCR}

In order to quantify the expression of $\mathrm{HBB}$ in ACL, ATC, PTC and exogenous expression in cell growth assay, real-time quantitative RT-PCR (Q-PCR) was performed. Q-PCR was carried with qPCR Mastermix for Syber Green I (Eurogenetec, Seraing, Belgium) and ABI 7700 (Applied Biosystems, Foster City, CA, USA) described previously (Onda et al, 2004b). Primers for Q-PCR of HBB were the same as those used in the SQ-PCR study. The template of Q-PCR was the same as that used in SQ-PCR, where the amount of cDNA monitoring of GAPDH expression was adjusted.

The expression difference between normal thyroid tissue and sample X in ACL, ATH and PTC is defined as follows:

$$
\begin{aligned}
& \Delta C_{\mathrm{tX}}=C_{\mathrm{t}-\mathrm{HBBX}}-C_{\mathrm{t}-\mathrm{GAPDHX}} \\
& \left(C_{\mathrm{t}-\mathrm{HBB}}, \mathrm{GAPDH}\right. \text { are threshold cycles for } \\
& \text { amplification of HBB and GAPDH, respectively })
\end{aligned}
$$

$$
\begin{aligned}
& \Delta C_{\mathrm{tN}-\text { ave }}=\text { Sum of } \Delta C_{\mathrm{tN} 1} \text { to } \Delta C_{\mathrm{tN} 5} / 5 \\
& \text { (average of } \Delta C_{\mathrm{t}} \text { of five normal thyroid tissues) }
\end{aligned}
$$

$$
\Delta \Delta C_{\mathrm{tX}}=\Delta C_{\mathrm{tX}}-\Delta C_{\mathrm{tN}-\text { ave }}
$$

Expression ratio of $\mathrm{HBB}$ to normal thyroid tissue (Sample X/ average of five normal thyroid tissues $)=2^{(-\Delta \Delta \mathrm{Ct} \mathrm{X})}$

\section{Immunohistochemical analysis}

To determine protein expression of $\mathrm{HBB}$, we performed immunohistochemical analyses using 14 paraffin-embedded samples of primary ATC and 15 PTC samples. ATC and PTC samples were collected at the Ito Hospital, Tokyo, Japan. In addition, for the evaluation of HBB expression in FTC, FAD and CTH, AccuMax thyroid cancer array and thyroid disease array (ISU ABXIS Co., Ltd, Seoul, South Korea) were applied. AntiHBB antibody was used (sc-21757, Santa Cruz Biotechnology, Inc., Santa Cruz, CA, USA) with 1:100 dilutions. Antigens were microwaved prior to immunostaining with VECTASTAIN Elite ABC kits (Vector Laboratories Inc., Burlingame, CA, USA) and Dako ENVISION kits (Dako corporation, Carpinteria, CA, USA) following the manufacturers' instructions. The sections were counterstained with haematoxylin, and then scanned at low power to identify areas that were evenly stained. Estimates of the numbers of positive cells were scored as follows: negative, $0 \% ; 1,1-10 \% ; 2,11-25 \% ; 3,26-50 \% ; 4,>50 \%$ positive (Saiz et al, 2002). Two independent investigators performed the estimation.

\section{Construction of HBB expression vector}

The expression vector of $\mathrm{HBB}$ was constructed with pcDNA3.1 directional Expression Kit (Invitrogen, Carlsbad, CA, USA) following the manufacturer's instruction with some modifications. First, to generate a full length of the coding sequence of $\mathrm{HBB}, \mathrm{PCR}$ was performed using cDNA that was reverse transcribed from pooled human placenta RNA. The cloning forward primer was $5^{\prime}-$ caccatggtgcatctgactcc- $3^{\prime}$, and reverse primer was $5^{\prime}$-gtgatacttgtgggccagggc $-3^{\prime}$. PCR condition was the same as that used in SQ-PCR. This reaction generated a $443 \mathrm{bp}$ PCR product that contained CACC sequence in front of the ATG start codon and deleted TAG stop codon from the original HBB sequence. The PCR product was electrophoresed with $2.0 \%$ NuSieve GTG agarose (Cambrex Bio Science Rockland Inc., Rockland, ME, USA) and 
stained with ethidium bromide. The proper size of the PCR product was excised and nucleic acid extracted with QIAquick Gel Extraction kit (QIAGEN, Tokyo, Japan). In all, $4 \mu \mathrm{l}$ of gel-extracted PCR product was ligated into pcDNA3.1 expression vector with 30 min incubation at room temperature. The ligated plasmid was mixed with $100 \mu \mathrm{l}$ of one-shot chemically competent Escherichia coli (Invitrogen) and incubated on ice for $30 \mathrm{~min}$, and then it was heat shocked at $42^{\circ} \mathrm{C}$ for $30 \mathrm{~s}$ and placed on ice immediately. Transformed E. coli was incubated in $300 \mu$ l of SOC medium (Invitrogen) at $37^{\circ} \mathrm{C}$ in the orbital shaker, and then $100 \mu \mathrm{l}$ of cultured SOC medium was plated on the LB plate containing $100 \mu \mathrm{g} \mathrm{ml}^{-1}$ ampicillin and it was incubated at $37^{\circ} \mathrm{C}$ for overnight. Several colonies were selected and sequences confirmed in the usual manner. Proper clone was incubated in $\mathrm{LB}$ medium at $37^{\circ} \mathrm{C}$ overnight and plasmid DNA was extracted using QIAfilter Plasmid Midi Kit (QIAGEN).
Transfection of HBB to KTA2 cell line and the evaluation of the exogenous expression of $\mathrm{HBB}$

In order to evaluate the effect of $\mathrm{HBB}$ in anaplastic thyroid cancer, $\mathrm{HBB}$ expression vector, pcDNA $\mathrm{HBB}$ expression vector was transfected into KTA2, which did not express HBB originally. The day before transfection, $1 \times 10^{3}$ of KTA2 cells were plated in a 24-well plate and cultured with the same condition as described previously. After $24 \mathrm{~h}$, the cells reached $60-70 \%$ confluence. Prior to transfection, the medium was changed to fresh RPMI1640. In all, $200 \mathrm{ng}$ of pcDNA HBB was mixed up to $50 \mu \mathrm{l}$ of Opti-MEM I medium (Invitrogen) and siPORT XP-1 (Ambion, Austin, TX, USA) subsequent to XP-1's instructions to make pcDNA HBB/XP-1 complex. The complex was transfected into arranged KTA2 and it was cultured up to 7 days. At the determined time points of days 0 , 3, 5 and 7, cells were collected and RNA was extracted with TRIzol

A

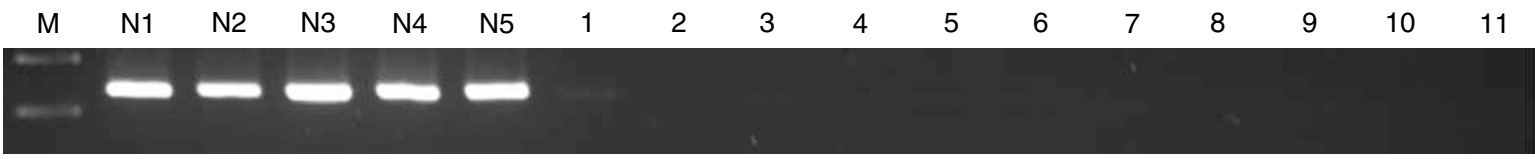

GAPDH

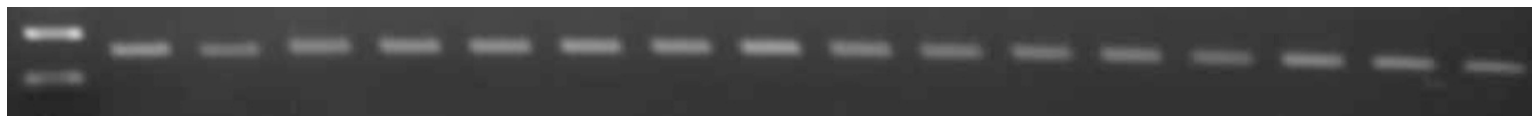

B

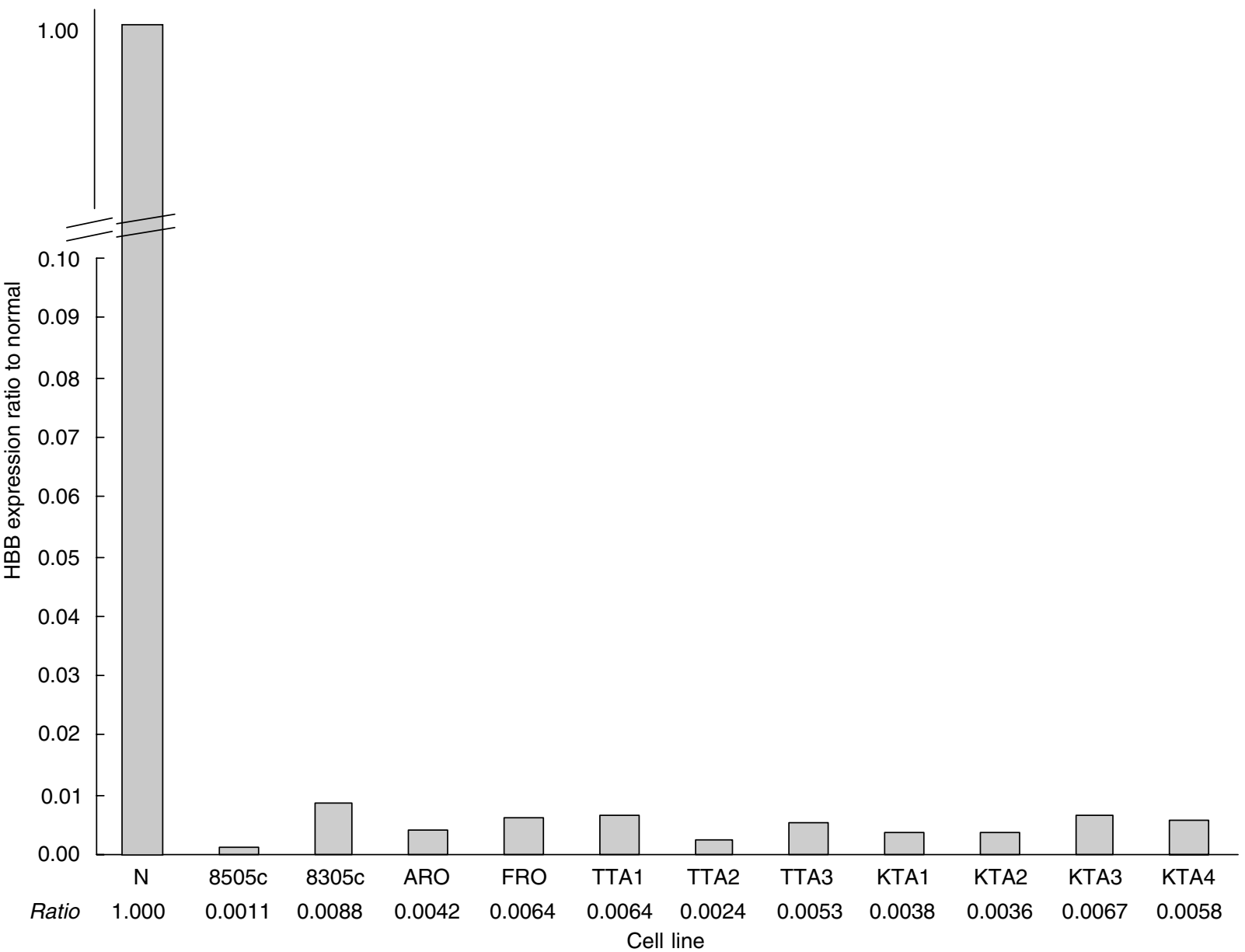

Figure I (A) Expression of HBB in ACLs. Compared to five normal thyroid gland expressions, HBB expression was significantly decreased in $A C L$ samples. M: size marker, NI -5: normal thyroid, I: 8305c, 2: 8505c, 3: ARO, 4: FRO, 5: TTA I, 6: TTA2, 7: TTA3, 8: KTAI, 9: KTA2, I0: KTA3, I I: KTA4. (B) Result of Q-PCR. The average expression of five normal thyroid glands was settled as 1.00 , and relative expression ratio compared to normal was calculated. Average expression of $\mathrm{HBB}$ in $\mathrm{ACL}$ was below $1 \%$ of normal thyroid gland. 
(Invitrogen, Carlsbad, CA, USA) (Onda et al, 2004b). The exogenous expression of HBB was confirmed with both SQ-PCR and Q-PCR in the same manner as described previously.

\section{Cell growth assay}

To determine the influence of gene expression of $\mathrm{HBB}$, cell growth assay (Smith et al, 2003) was carried out. In total, 3000 KTA2 cells were plated on a 24 -well plate and, after $24 \mathrm{~h}, 200 \mathrm{ng}$ of pcDNA HBB plasmid was transfected. Cells were fixed with $10 \%$ formalin for $10 \mathrm{~min}$ at the determined time points, $0,3,5$ and 7 days after transfection. After washing two times in water, fixed cells were stained with $0.1 \%$ crystal violet for $10 \mathrm{~min}$, and then washed three times with water to remove the excess crystal violet solution. The stained crystal violet was eluted with $200 \mu \mathrm{l}$ of $10 \%$ acetic acid and the absorbance of $590 \mathrm{~nm}$ was measured with a spectrophotometer. The difference of cell growth was calculated using Student's $t$-test. This statistical procedure was performed by Statview version 5.0 (SAS Institute Inc., Cary, NC, USA). The experiments were triplicated.

\section{Single-strand conformation polymorphism (SSCP) analysis of HBB gene}

In order to analyse mutation in the HBB gene, PCR-SSCP analysis was carried out (Onda et al, 1997; Harada et al, 2002). Genomic DNA was extracted from 11 ACLs in a usual manner. With regard to the entire coding region of $\mathrm{HBB}$, the first exon to the third exon were examined. The primers used for SSCP were as follows: (exon 1) $1 \mathrm{~F}: 5^{\prime}$-agcaacctcaaacagacacc- $3^{\prime}, 1 \mathrm{R}: 5^{\prime}$-gtctccacatgcccagtttc- $3^{\prime}$, (exon 2) 2F: $5^{\prime}$-ttggtctattttcccaccctta- $3^{\prime}, 2 \mathrm{R}: 5^{\prime}$-tcaagcgtcccatagactca-3', (exon 3) 3F: $5^{\prime}$-cctcttatcttcctcccacag-3', 3R: $5^{\prime}$-gatgctcaaggcccttcata- $3^{\prime}$. These primers were designed to cover the
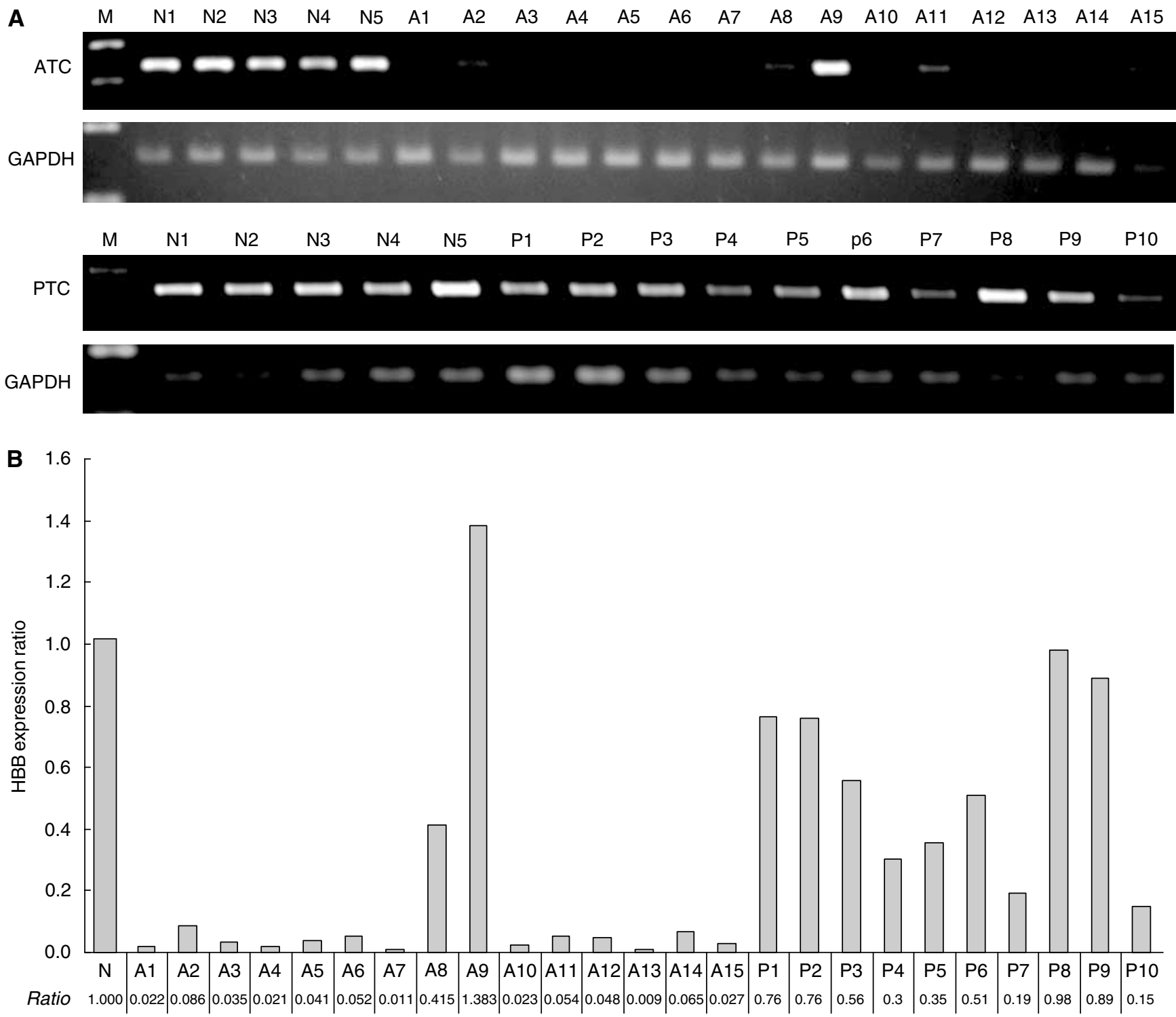

Figure 2 (A) Expression of HBB in primary thyroid cancer by SQ-PCR. In primary ATC samples, HBB expression was decreased compared to normal thyroid gland. On the contrary, HBB expression was almost equal to the expression of normal thyroid glands. M: size marker, NI - 5: normal thyroid, AI - I5, primary anaplastic thyroid cancer samples (ATC), PI-10, primary PTC samples. (B) Relative expression of HBB to normal thyroid gland is presented. Haemoglobin beta expression of normal thyroid is the average of five normal thyroid glands. When the expression of normal thyroid was settled as I.00, the ratio represented relative expression of HBB in the sample. 


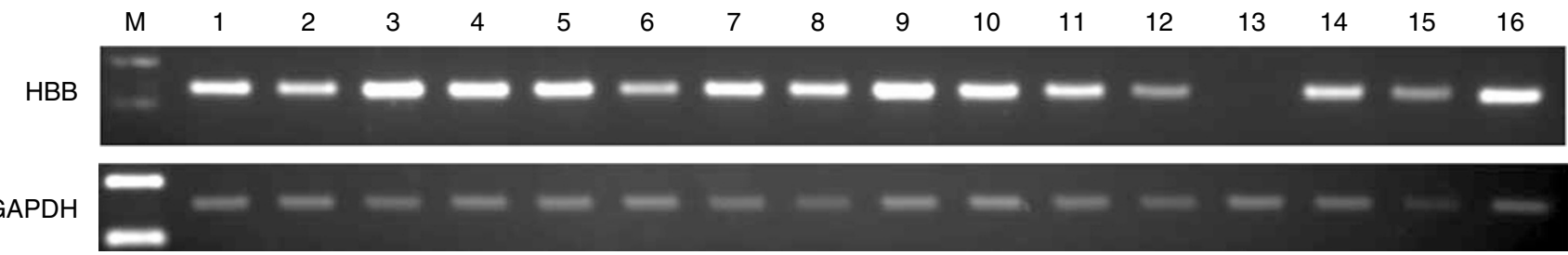

Figure 3 Expression of HBB in 16 normal human tissues. Haemoglobin beta was expressed ubiquitously except in the ovary. M, size marker, I. Heart, 2. Whole brain, 3. Placenta, 4. Lung, 5. Liver, 6. Skeletal muscle, 7. Kidney, 8. Pancreas, 9. Spleen, 10. Thymus, II. Prostate, 12. Testis, 13. Ovary, 14. Small intestine, 15. Colon, 16. Leukocyte.

entire exon of the HBB gene. Heat-denatured PCR product was electrophoresed on a $6 \%$ long ranger gel (Cambrex, East Rutherford, NJ, USA) with $5 \%$ glycerol, $5 \mathrm{~W}$ for $4 \mathrm{~h}$. DNA fragments were visualised by silver staining using the Plus One DNA silver-staining kit (Pharmacia Biotech, Tokyo, Japan) following the manufacturer's manual.

\section{Methylation-specific PCR in the promoter legion of the HBB gene}

In order to evaluate the methylation status of the promoter region of the HBB gene, methylation-specific PCR analysis (MSP) was performed. Genomic DNA from 11 ACLs was bisulphite modificated using the CpGenome DNA modification kit (CHEMICOM International, Inc., Temecula, CA, USA) following the manufacturer's instruction. Sequence information of the promoter region of the HBB gene was downloaded from UCSC genome browser (http:// genome.cse.ucsc.edu/cgi-bin/hgGateway) and primers for MSP were designed with Methprimer program (http://www.ucsf.edu/urogene/ methprimer/index1.html). Primers used for MSP are as follows: for methylated DNA (M), forward: 5'-ttagaagagttaaggataggtacgg-3'; reverse: $5^{\prime}$-taccccacaaaacaataacgac- $3^{\prime}$; for unmethylated DNA (UM), forward: $5^{\prime}$-ttagaagagttaaggataggtatgg- $3^{\prime}$; reverse: $5^{\prime}$-cttaccccacaaaacaataacaac- $3^{\prime}$. The size of PCR products was 250 and $252 \mathrm{bp}$.

\section{RESULTS}

\section{Expression of HBB in ACLs, primary ATC and PTC}

In order to evaluate the expression of HBB in ACLs, SQ-PCR and $\mathrm{Q}-\mathrm{PCR}$ were performed. Compared to normal thyroid glands that were derived from five PTC patients, expression of HBB was significantly decreased in 11 ACLs (Figure $1 \mathrm{~A}$ and B). Average expression of $\mathrm{HBB}$ in ACL was below $1 \%$ of the average expression in a normal thyroid gland.
A

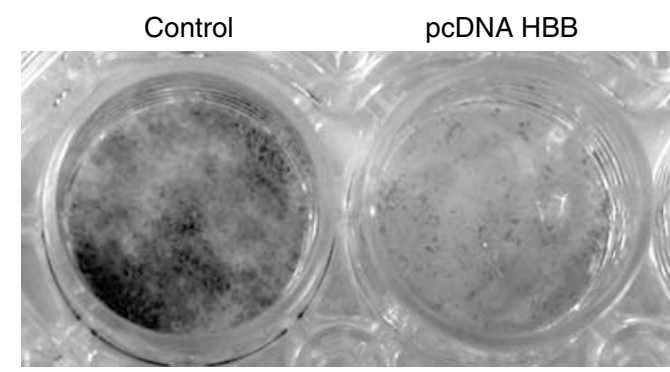

Day 7

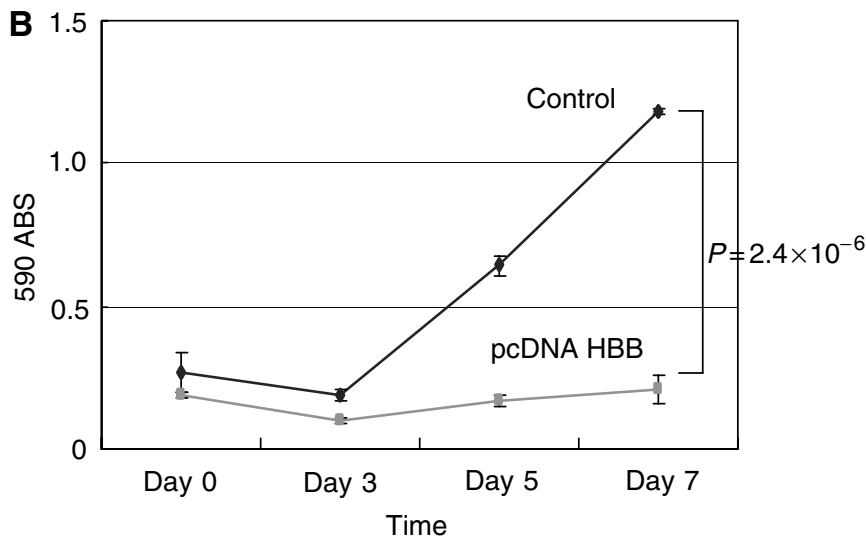

Figure 5 The results of cell growth assay. (A) Representative image of KTA2 staining with crystal violet. The cells were stained at 7 days after transfection. Control, transfected KTA2 with pcDNA empty vector, $\mathrm{HBB}$, transfected KTA2 with pcDNA HBB expression vector. The experiments were triplicated. (B) Graphical view of KTA2 cell growth. Compared to control, $p C D N A$ HBB transfected cell showed growth suppression $\left(P=2.4 \times 10^{-6}\right.$, at the point of day $7, t$-test). 
Then, HBB expression was assessed with ATC and PTC samples. In ATC, the expression of $\mathrm{HBB}$ was significantly decreased as seen in ACLs, except in one case (A9), with SQ-PCR and Q-PCR assay. Haemoglobin beta expression in ATC was $0.9-8.6 \%$ of normal thyroid gland expression, besides A8 and A9 cases. On the other hand, in PTC samples, expression of HBB was $15-98 \%$ of normal thyroid. Even in PTC cases, decreased HBB expression was observed; however, the expression of $\mathrm{HBB}$ in PTC was higher than that in ATC (Figure 2A and B).

To validate the expression of $\mathrm{HBB}$ in other human normal tissues, SQ-PCR was achieved with 16 human normal tissues. As shown in Figure 3, HBB was expressed in all tissues, besides the ovary, with various intensities. These results presented that $\mathrm{HBB}$ was expressed ubiquitously in normal human tissues including the thyroid gland.

\section{Construction of HBB expression vector and forced expression in KTA2 cell}

Using pcDNA 3.1 plasmid, HBB expression vector, namely pcDNA $\mathrm{HBB}$, was developed. To confirm forced expression of $\mathrm{HBB}$, pcDNA HBB was transfected into KTA2 and RNA was collected at
A
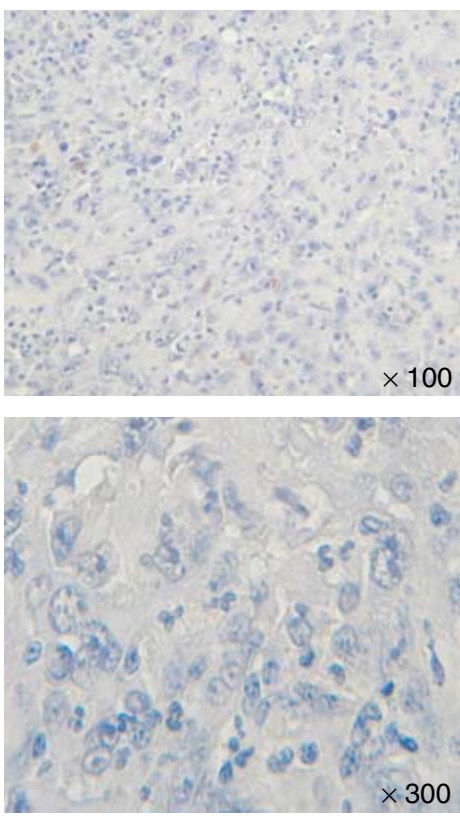
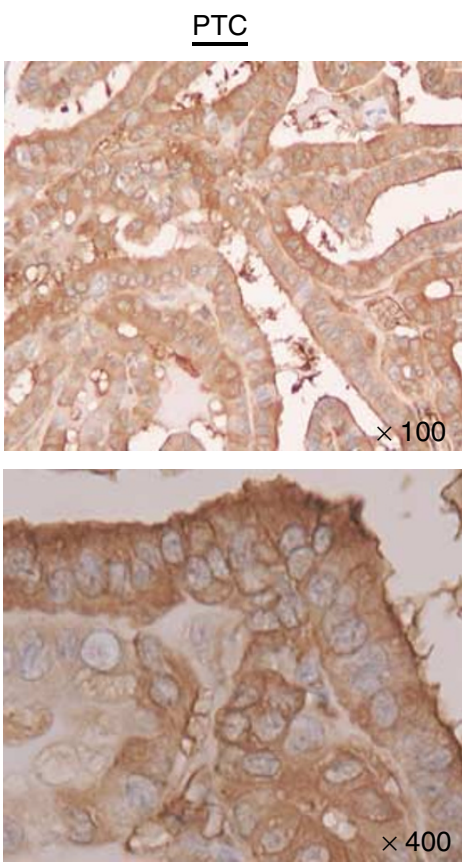
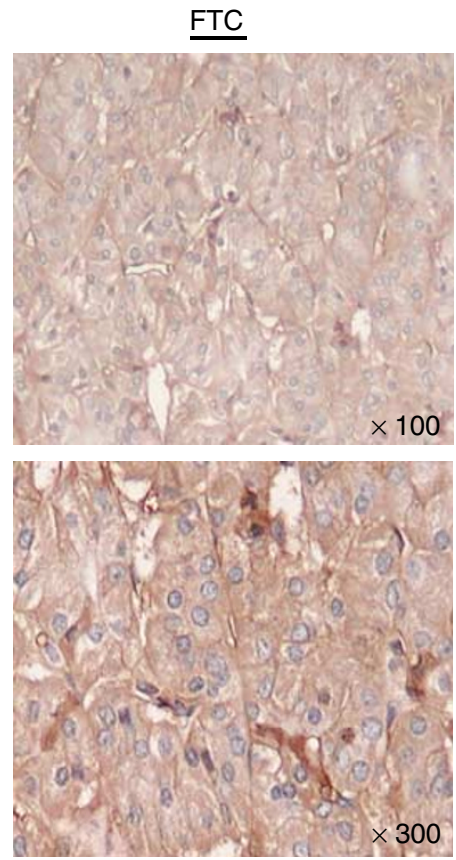

B
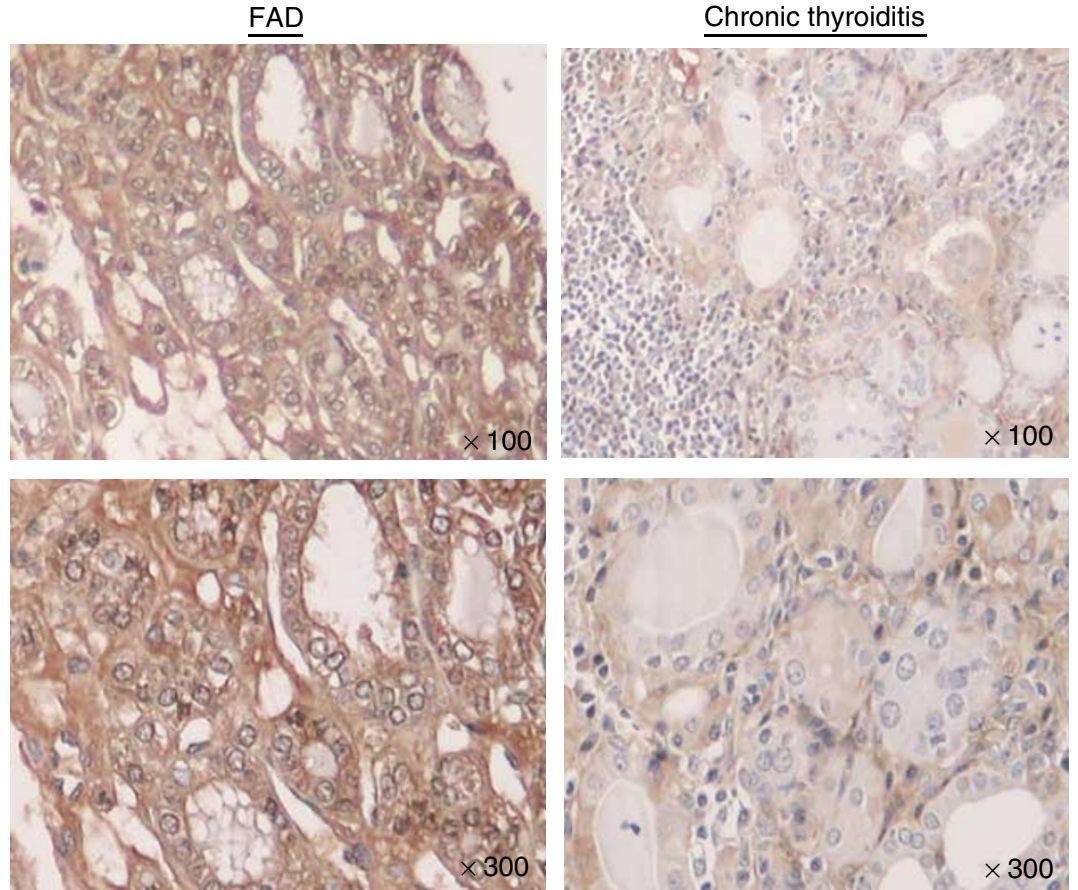

Figure 6 Immunohistochemical analysis of HBB expression. (A) Little expression of HBB was confirmed in ATC samples. On the contrary, HBB expressed in PTC and FTC, mainly stained in cytoplasm. Upper: $\times 100$, lower: $\times 300$ and $\times 400$. (B) Haemoglobin beta expressed in FDA and CTH. However, less staining was seen in $\mathrm{CTH}$, compared to other histological types. 
days $0,3,5$ and 7. Exogenous expression of $\mathrm{HBB}$ within transfected KTA2 cell line was confirmed with SQ-PCR and Q-PCR analysis (Figure 4). Compared to the control, HBB expression was upregulated in transfected KTA2.

\section{Cell growth assays}

In order to clarify the effect of HBB in cell growth, cell growth assay was performed. KTA2 cells that were transfected pcDNA HBB showed the suppression of cell growth, compared to the control (Figure 5A). Haemoglobin beta-transfected cells showed a

Table I Score of HBB expression with immunostaining method

\begin{tabular}{lllll}
\hline ATC & PTC & FTC & FAD & CTH
\end{tabular}

Case Score ${ }^{a}$ Case Score ${ }^{a}$ Case Score $^{a}$ Case Score $^{\text {a }}$ Case Score $^{\text {a }}$

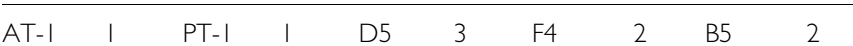

AT-2 $0 \quad$ PT-2

AT-3 I PT-3

AT-4 0 PT-4

AT-5 0 PT-5

AT-6 0 PT-6

$\begin{array}{lll}\text { AT-7 } & 2 & \text { PT-7 }\end{array}$

AT-8 0 PT-8

AT-9 | PT-9

AT-10 $0 \quad$ PT-10

AT-I| | PT-I| 2

AT-12 $2 \quad$ PT-12 3

AT-13 $2 \quad$ PT-13 4

AT-14 $0 \quad$ PT-14 3

PT- 15 |

Ave. 0.71 Ave. 2.53 Ave. 3.33 Ave. 2.8 Ave. 1.6

${ }^{a}$ Estimates of the numbers of positive cells; negative, $0 \%, 1,1-10 \% ; 2,11-25 \% ; 3$, $26-50 \% ; 4,>50 \%$ positive. slow-growing curve (Figure $5 \mathrm{~B}$ ), and, at the point of day 7 , the difference of cell growth between pcDNA HBB-transfected cells and pcDNA empty vector-transfected cells (control) reached statistical significance $\left(P=2.4 \times 10^{-6}\right)$.

\section{Immunohistochemical analysis of HBB expression with ATC, PTC, FTC, FAD and CTH}

To evaluate $\mathrm{HBB}$ protein expression, immunohistochemical analysis was performed with 14 primary ATC and 15 PTC samples. In addition, using tissue microarray, nine FTC, five FAD and five CTH samples were assessed. In PTC, HBB expression was confirmed with strong intensity and the average score was 2.53 . On the contrary, weak expression was seen in ATC samples (Figure 6A), and the average score was 0.71 (Table 1). In FTC, FAD and $\mathrm{CTH}$, stronger expression of $\mathrm{HBB}$ was seen compared to ATC samples (Figure 6A and $\mathrm{B}$ ), and the average staining scores were $3.33,2.8$ and 1.6 , respectively.

\section{Mutation analysis of HBB gene}

In order to detect the mutation of $\mathrm{HBB}$ gene, SSCP analysis was performed using genomic DNA from 11 ACLs. No mutation from exon 1 to 3 was seen in 11 ACL samples (Figure 7).

\section{Methylation-specific PCR}

To evaluate the methylation status of the HBB promoter region, MSP assay was carried out with 11 ACL. Within 10 cell lines except KTA2, PCR product was seen both in M and UM primer sets. Only KTA2 was not methylated in the promoter region. This result showed that the promoter region of HBB gene was mainly hemimethylated and it suggested that methylation was one of the reasons of downregulation of $\mathrm{HBB}$ expression in anaplastic thyroid cancer (Figure 8).

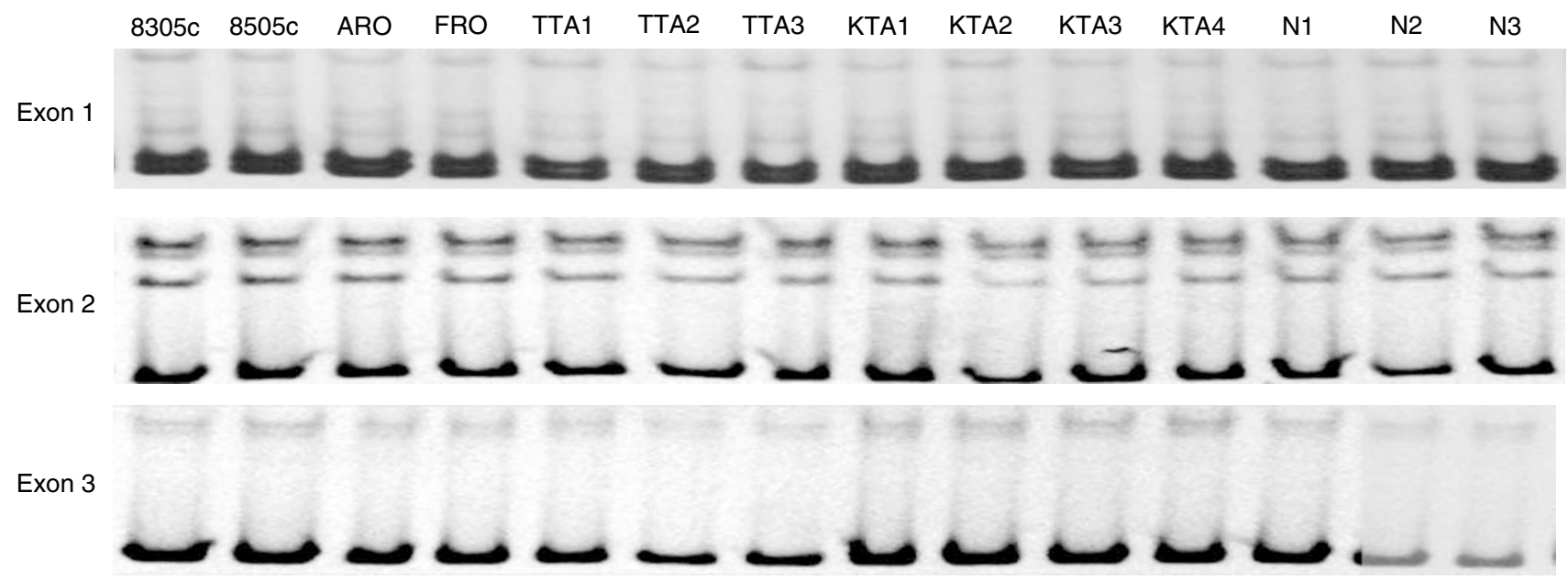

Figure 7 Results of SSCP analysis of HBB gene with I I ACLs and three normal thyroid glands. Within coding region from exon I to 3, no mutation was confirmed.

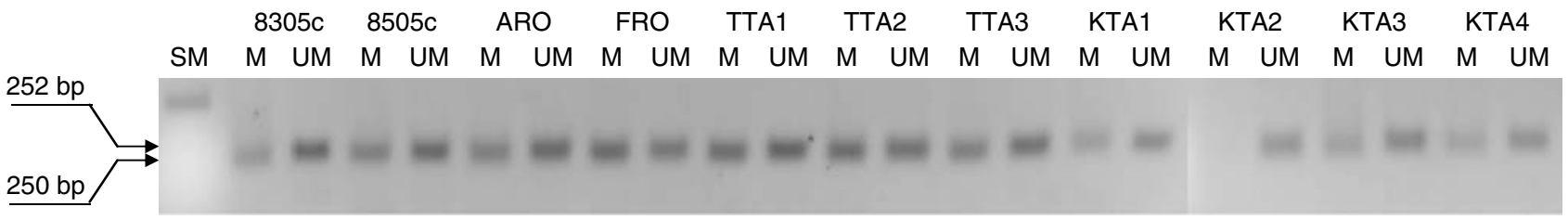

Figure 8 Results of MSP analysis within the promoter region of HBB gene with I I ACLs. Generally speaking, all ACL were hemimethylated in the promoter region except KTA2. Only KTA2 was not methylated in this region. 


\section{DISCUSSION}

Haemoglobin beta is one of the globins chain components of haemoglobin A, whose basic function is oxygen transport (Giardina et al, 1995). There are several reasons for the reduction of HBB expression; for example, partial deletion of the terminal portion of HBB gene (Orkin et al, 1979), nonsense mutation (Chang and Kan, 1979) and frameshift deletion (Orkin and Goff, 1981) cause beta-thalassemia.

Genetically, HBB locates at 11p15.5 (Bepler et al, 1999) and this locus contains embryonic and adult beta-like globin genes that are ordered as they are expressed during development. High-level expression of the beta-globin gene cluster is regulated by the locus control region (LCR) (Sawado et al, 2003). Also, at this locus, loss of imprinting (LOI) had been reported in head and neck squamous cell cancers (Rainho et al, 2001). Thus, chromosomal location of $11 \mathrm{p} 15.5$ is interesting from the viewpoint of human genetics. In addition, there were several reports of $\mathrm{LOH}$ in various kinds of cancers at this locus. In this region, there were two distinct tumour-suppressor loci that implicated breast cancer progression and metastasis (Karnik et al, 1998). It is suggested that an LOH of $11 \mathrm{p} 15.5$ might relate to poor prognosis of nonsmall-cell lung cancer (Bepler et al, 2002). We previously reported up to $33 \% \mathrm{LOH}$ at this locus in primary ATC (Kitamura et al, 2000a). Considering these results, it is highly suggested that novel tumour suppressor genes might be exist at this locus.

In this report, we showed the significant decreased expression of HBB in ACL and ATC samples. This is the first report of decreased expression of $\mathrm{HBB}$ in anaplastic thyroid cancer. On the other hand, HBB expression was seen in normal thyroid gland, PTC, FTC, FAD and $\mathrm{CTH}$ samples. In addition, expression of $\mathrm{HBB}$ was observed in other normal human tissue ubiquitously.

Generally speaking, it is considered that a large part of ATC arises from differentiated thyroid cancer with anaplastic transformation (Hunt et al, 2003). Thus, our results suggest the possibility that loss of expression HBB might relate to anaplastic transformation of differentiated thyroid cancer.
To clarify the role of HBB in cancer cell growth, cell growth assay was performed with ACL KTA2, which has no expression of HBB basically. Interestingly, exogenous expression of HBB suppressed the cell growth significantly. Our results presented the possibility of the tumour suppressor activity of $\mathrm{HBB}$. There are several reasons for gene silencing, including $\mathrm{LOH}$ and methylation of promoter regions. In this study, $\mathrm{LOH}$ was not examined because normal-tumour paired DNA was not available. However, methylation-specific PCR in ACLs revealed the hemimethylated status of the promoter region of the $\mathrm{HBB}$ gene. With regard to mutation search, there was no mutation in the coding region of the $\mathrm{HBB}$ gene. Considering these results, it was suggested that methylation of the promoter region was one of the reasons for the downregulation of the HBB gene. However, we could not detect promoter methylation in KTA2 cell; so it is also suggested that there might be other mechanisms besides promoter methylation for the downregulation of HBB expression in anaplastic thyroid cancer.

Haemoglobin beta is one of the well-investigated genes in the field of blood diseases. However, nobody paid attention to this gene in the field of 'cancer'. Even physiologically, HBB expression is controlled intricately (Stamatoyannopoulos, 2005). In the viewpoint of cancer genetics, it strongly required further examination of the mechanism of the downregulation of HBB in anaplastic thyroid cancer.

\section{ACKNOWLEDGEMENTS}

We thank Naoko Tsuruta, Mayumi Tanaka and Junko Sato for excellent secretarial assistance. This work was supported by special grants for Strategic Advanced Research on 'Cancer' from the Ministry of Education, Science, Sports and Culture of Japan, and by a Research for the Future Program Grant of The Japan Society for the Promotion of Science.

\section{REFERENCES}

Bepler G, Gautam A, McIntyre LM, Beck AF, Chervinsky DS, Kim YC, Pitterle DM, Hyland A (2002) Prognostic significance of molecular genetic aberrations on chromosome segment 11 p15.5 in non-small-cell lung cancer. J Clin Oncol 20: $1353-1360$

Bepler G, O’Briant KC, Kim YC, Schreiber G, Pitterle DM (1999) A 1.4-Mb high-resolution physical map and contig of chromosome segment 11 p15.5 and genes in the LOH11A metastasis suppressor region. Genomics 55: $164-175$

Chang JC, Kan YW (1979) beta 0 thalassemia, a nonsense mutation in man. Proc Natl Acad Sci USA 76: 2886-2889

Garcia-Rostan G, Tallini G, Herrero A, D'Aquila TG, Carcangiu ML, Rimm DL (1999) Frequent mutation and nuclear localization of beta-catenin in anaplastic thyroid carcinoma. Cancer Res 59: $1811-1815$

Giardina B, Messana I, Scatena R, Castagnola M (1995) The multiple functions of hemoglobin. Crit Rev Biochem Mol Biol 30: 165-196

Harada H, Yoshida S, Nobe Y, Ezura Y, Atake T, Koguchi T, Emi M (2002) Genomic structure of the human NLK (nemo-like kinase) gene and analysis of its promoter region. Gene 285: 175-182

Hunt JL, Tometsko M, LiVolsi VA, Swalsky P, Finkelstein SD, Barnes EL (2003) Molecular evidence of anaplastic transformation in coexisting well-differentiated and anaplastic carcinomas of the thyroid. Am J Surg Pathol 27: 1559- 1564

Karnik P, Paris M, Williams BR, Casey G, Crowe J, Chen P (1998) Two distinct tumor suppressor loci within chromosome $11 \mathrm{p} 15$ implicated in breast cancer progression and metastasis. Hum Mol Genet 7: $895-903$

Kitamura Y, Shimizu K, Tanaka S, Ito K, Emi M (2000a) Allelotyping of anaplastic thyroid carcinoma: frequent allelic losses on 1q, 9p, 11, 17, 19p, and 22q. Genes Chromosomes Cancer 27: 244-251
Kitamura Y, Shimizu K, Tanaka S, Ito K, Emi M (2000b) Association of allelic loss on 1q, 4p, 7q, 9p, 9q, and $16 \mathrm{q}$ with postoperative death in papillary thyroid carcinoma. Clin Cancer Res 6: 1819-1825

Launonen V, Mannermaa A, Stenback F, Kosma VM, Puistola U, Huusko P, Anttila M, Bloigu R, Saarikoski S, Kauppila A, Winqvist R (2000) Loss of heterozygosity at chromosomes $3,6,8,11,16$, and 17 in ovarian cancer: correlation to clinicopathological variables. Cancer Genet Cytogenet 122: $49-54$

Nakamura T, Yana I, Kobayashi T, Shin E, Karakawa K, Fujita S, Miya A, Mori T, Nishisho I, Takai S (1992) p53 gene mutations associated with anaplastic transformation of human thyroid carcinomas. Jpn J Cancer Res 83: $1293-1298$

Onda M, Abe R, Tsuchiya A, Fukushima T, Ando Y, Yoshida T (1997) K-ras and p53 gene mutations in colorectal cancer in 57 Japanese patients. Fukushima J Med Sci 43: 29-39

Onda M, Emi M, Yoshida A, Miyamoto S, Akaishi J, Asaka S, Mizutani K, Shimizu K, Nagahama M, Ito K, Tanaka T, Tsunoda T (2004a) Comprehensive gene expression profiling of anaplastic thyroid cancers with cDNA microarray of 25344 genes. Endocrine-Relat Cancer 11: 843-854 Onda M, Nagai H, Yoshida A, Miyamoto S, Asaka S, Akaishi J, Takatsu K, Nagahama M, Ito K, Shimizu K, Emi M (2004b) Up-regulation of transcriptional factor E2F1 in papillary and anaplastic thyroid cancers. J Hum Genet 49: 312-318

Orkin SH, Goff SC (1981) Nonsense and frameshift mutations in beta 0 -thalassemia detected in cloned beta-globin genes. $J$ Biol Chem 256: $9782-9784$

Orkin SH, Old JM, Weatherall DJ, Nathan DG (1979) Partial deletion of beta-globin gene DNA in certain patients with beta 0-thalassemia. Proc Natl Acad Sci USA 76: 2400-2404 
Ozaki O, Ito K, Mimura T, Sugino K (1999) Anaplastic transformation of papillary thyroid carcinoma in recurrent disease in regional lymph nodes: a histologic and immunohistochemical study. J Surg Oncol 70: 45-48

Passler C, Scheuba C, Prager G, Kaserer K, Flores JA, Vierhapper H, Niederle B (1999) Anaplastic (undifferentiated) thyroid carcinoma (ATC). A retrospective analysis. Langenbecks Arch Surg 384: 284-293

Pauws E, Tummers RF, Ris-Stalpers C, de Vijlder JJ, Voute T (2001) Absence of activating mutations in ras and gsp oncogenes in a cohort of nine patients with sporadic pediatric thyroid tumors. Med Pediatr Oncol 36: 630-634

Persons DA (2003) Update on gene therapy for hemoglobin disorders. Curr Opin Mol Ther 5: 508-516

Rainho CA, Kowalski LP, Rogatto SR (2001) Loss of imprinting and loss of heterozygosity on $11 \mathrm{p} 15.5$ in head and neck squamous cell carcinomas. Head Neck 23: $851-859$

Roy D, Calaf G, Hei TK (2003) Allelic imbalance at 11p15.5-15.4 correlated with c-Ha-ras mutation during radiation-induced neoplastic transformation of human breast epithelial cells. Int J Cancer 103: 730-737

Saiz AD, Olvera M, Rezk S, Florentine BA, McCourty A, Brynes RK (2002) Immunohistochemical expression of cyclin D1, E2F-1, and Ki-67 in benign and malignant thyroid lesions. J Pathol 198: 157-162

Sawado T, Halow J, Bender MA, Groudine M (2003) The beta-globin locus control region (LCR) functions primarily by enhancing the transition from transcription initiation to elongation. Genes Dev 17: 1009-1018
Schiebe M, Ohneseit P, Hoffmann W, Meyermann R, Rodemann HP, Bamberg M (2001) Loss of heterozygosity at 11p15 and p53 alterations in malignant gliomas. J Cancer Res Clin Oncol 127: 325 - 328

Smith LL, Coller HA, Roberts JM (2003) Telomerase modulates expression of growth-controlling genes and enhances cell proliferation. Nat Cell Biol 5: $474-479$

Stamatoyannopoulos G (2005) Control of globin gene expression during development and erythroid differentiation. Exp Hematol 33: 259-271

Thein SL, Hesketh C, Taylor P, Temperley IJ, Hutchinson RM, Old JM, Wood WG, Clegg JB, Weatherall DJ (1990) Molecular basis for dominantly inherited inclusion body beta-thalassemia. Proc Natl Acad Sci USA 87: $3924-3928$

Voutilainen PE, Multanen M, Haapiainen RK, Leppaniemi AK, Sivula AH (1999) Anaplastic thyroid carcinoma survival. World J Surg 23: 975 - 978; discussion $978-979$

Xu XL, Wu LC, Du F, Davis A, Peyton M, Tomizawa Y, Maitra A, Tomlinson G, Gazdar AF, Weissman BE, Bowcock AM, Baer R, Minna JD (2001) Inactivation of human SRBC, located within the 11p15.5-p15.4 tumor suppressor region, in breast and lung cancers. Cancer Res 61: $7943-7949$

Yasuda J, Ichikawa T, Tsuruga M, Matsuoka A, Sugawara Y, Shikama K (2002) The alpha 1 beta 1 contact of human hemoglobin plays a key role in stabilizing the bound dioxygen. Eur J Biochem 269: 202-211 